\title{
Simulation, Optimization, and Machine Learning in Sustainable Transportation Systems: Models and Applications
}

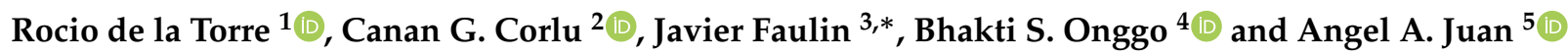 \\ 1 INARBE Institute, Department of Business Management, Public University of Navarre, \\ 31006 Pamplona, Spain; rocio.delatorre@unavarra.es \\ 2 Metropolitan College, Boston University, Boston, MA 02215, USA; canan@bu.edu \\ 3 Institute of Smart Cities, Department of Statistics, Computer Science, and Mathematics, \\ Public University of Navarre, 31006 Pamplona, Spain \\ 4 Centre for Operational Research Management Sciences and Information Systems (CORMSIS), \\ University of Southampton, Southampton SO17 1BJ, UK; b.s.s.onggo@soton.ac.uk \\ 5 IN3-Computer Science Department, Universitat Oberta de Catalunya \& Euncet Business School, \\ 08018 Barcelona, Spain; ajuanp@uoc.edu \\ * Correspondence: javier.faulin@unavarra.es
}

Citation: de la Torre, R.; Corlu, C.G.; Faulin, J.; Onggo, B.S.; Juan, A.A. Simulation, Optimization, and Machine Learning in Sustainable Transportation Systems: Models and Applications. Sustainability 2021, 13, 1551. https://doi.org/10.3390/ su13031551

Received: 28 December 2020

Accepted: 26 January 2021

Published: 2 February 2021

Publisher's Note: MDPI stays neutral with regard to jurisdictional claims in published maps and institutional affiliations.

Copyright: (c) 2021 by the authors. Licensee MDPI, Basel, Switzerland. This article is an open access article distributed under the terms and conditions of the Creative Commons Attribution (CC BY) license (https:/ / creativecommons.org/licenses/by/ $4.0 /)$.

\begin{abstract}
The need for effective freight and human transportation systems has consistently increased during the last decades, mainly due to factors such as globalization, e-commerce activities, and mobility requirements. Traditionally, transportation systems have been designed with the main goal of reducing their monetary cost while offering a specified quality of service. During the last decade, however, sustainability concepts are also being considered as a critical component of transportation systems, i.e., the environmental and social impact of transportation activities have to be taken into account when managers and policy makers design and operate modern transportation systems, whether these refer to long-distance carriers or to metropolitan areas. This paper reviews the existing work on different scientific methodologies that are being used to promote Sustainable Transportation Systems (STS), including simulation, optimization, machine learning, and fuzzy sets. This paper discusses how each of these methodologies have been employed to design and efficiently operate STS. In addition, the paper also provides a classification of common challenges, best practices, future trends, and open research lines that might be useful for both researchers and practitioners.
\end{abstract}

Keywords: transportation systems; sustainability; simulation; optimization; machine learning

\section{Introduction}

The United Nations defines sustainable development as the development that meets the needs of the present without compromising the ability of future generations to meet their own needs [1]. To achieve sustainable development, we need to harmonize economic growth, social inclusion and environmental protection. In fact, ensuring energy security, mitigating climate change, and improving air quality in the most populated areas (urban areas) has become one of the main concerns of governments. One of the sectors that have a significant impact on the above problems is the transportation sector [2,3]. The main challenge for a transportation system to be sustainable is how to design it so that it is economically viable, benefits all people-especially those whose livelihoods depend on a good transportation system - and is environmentally friendly. Sustainable transportation plays a fundamental role in the socio-economic development of a country and considers three different dimensions: economic development, environmental preservation, and social development [4]. Obviously, these dimensions are not isolated, they are interrelated with each other, which not only adds complexity to the system [5], but also forces the decision-making process to be done in an integrative way, i.e., encompassing the three aforementioned dimensions. More specifically, a sustainable transportation system is essential to guarantee: (i) mobility and efficient access for all users, thus promoting equity 
among citizens; (ii) a safe and environmentally friendly mode of transportation; (iii) an economically sustainable system; and (iv) public health, since high levels of pollution in cities have been associated with serious health problems, i.e., cardio-respiratory morbidity, mortality, and cancer [6,7].

This variety of dimensions can also be observed in the main group of stakeholders (i.e., government, users, and the community). In this regard, Li et al. [8] consider that the implementation of sustainable practices covers not only the social considerations of the final users, but also the health and safety issues of the whole community. Furthermore, the implementation of good practices is promoted by the governments themselves, who can see how the new paradigm can bring benefits to citizens, improving their quality of life, and favoring the survival of companies.

The decisions related to sustainable transportation boosted by governments and legislators are also diverse in their nature, and in recent years their focus has been on alleviating traffic congestion in highly urbanized areas and on developing alternative transportation systems to traditional ones that minimize the emission of pollutants, e.g., the implementation of policies that favor the use of bicycles or public transport. All these strategies and decisions go through the identification of user preferences regarding communication routes, transportation methods, and consumption habits, among others. That is why the use of tools such as simulation, optimization, and machine learning, is a fundamental aid for the decision-making process [9]. Figure 1 shows the time evolution, since 2010, of the number of Scopus-indexed articles that contain in their title or abstract the combination of words "sustainable transportation" (or "sustainable transportation") and each of the following combinations: "machine learning" or "artificial intelligence", "optimization", "simulation", or "fuzzy". One can notice that both simulation and optimization are the most popular and fast-growing methodologies when addressing sustainability transportation issues. Still, the use of machine learning/artificial intelligence methods and fuzzy techniques is also gaining popularity in recent years.

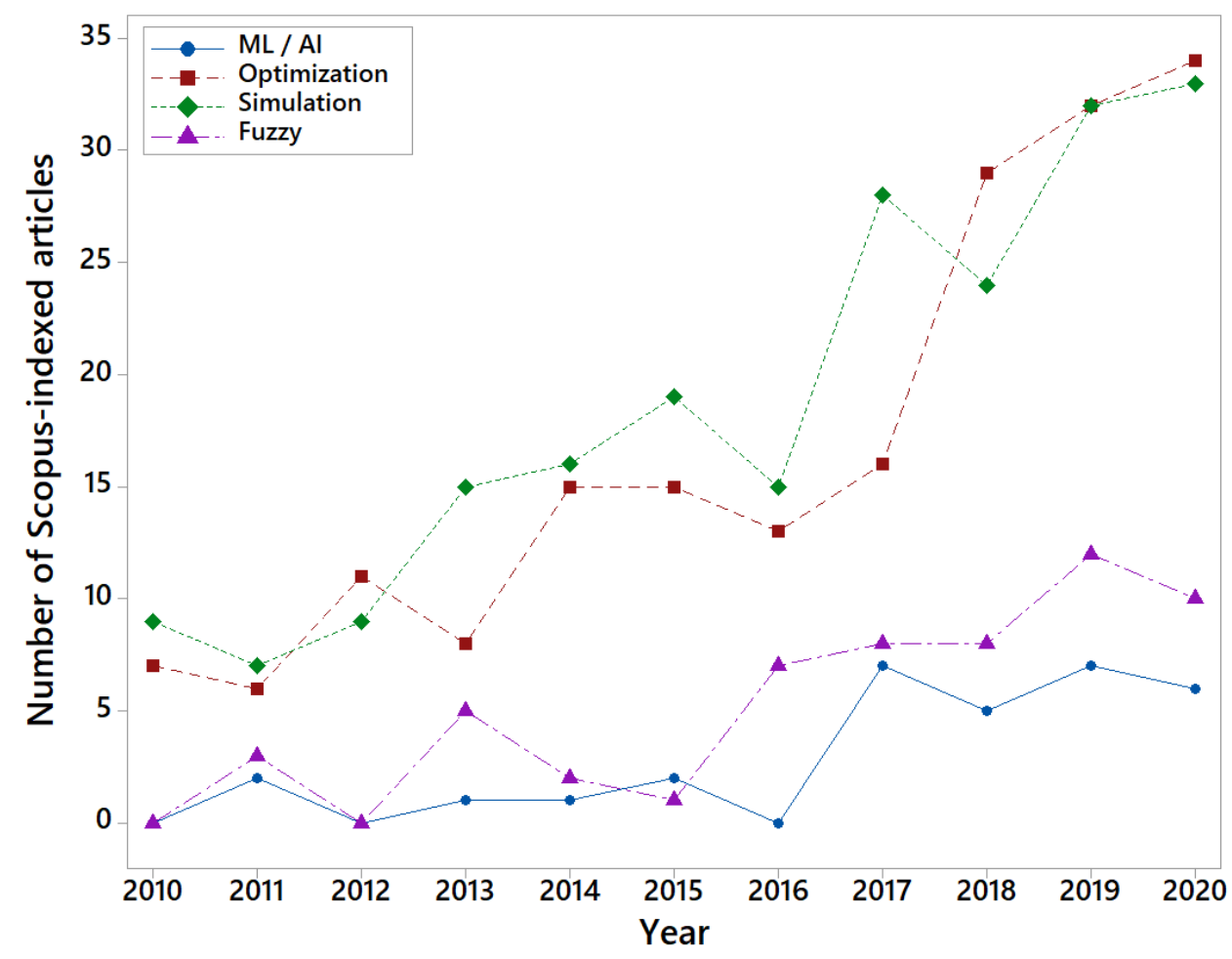

Figure 1. Evolution of Scopus-indexed articles on "sustainable transportation" by methodology.

Likewise, Figure 2 show the number of Scopus-indexed publications, per journal, that contain the terms "sustainable transportation" in their title, abstract, or keywords 
(only journals with 20 or more articles have been considered in this figure). Notice that the journal 'Sustainability' is clearly leading this ranking, followed by other three popular journals in the area of transportation: 'Transportation Policy', 'Journal of Transportation Geography', and 'Transportation Research Procedia'.

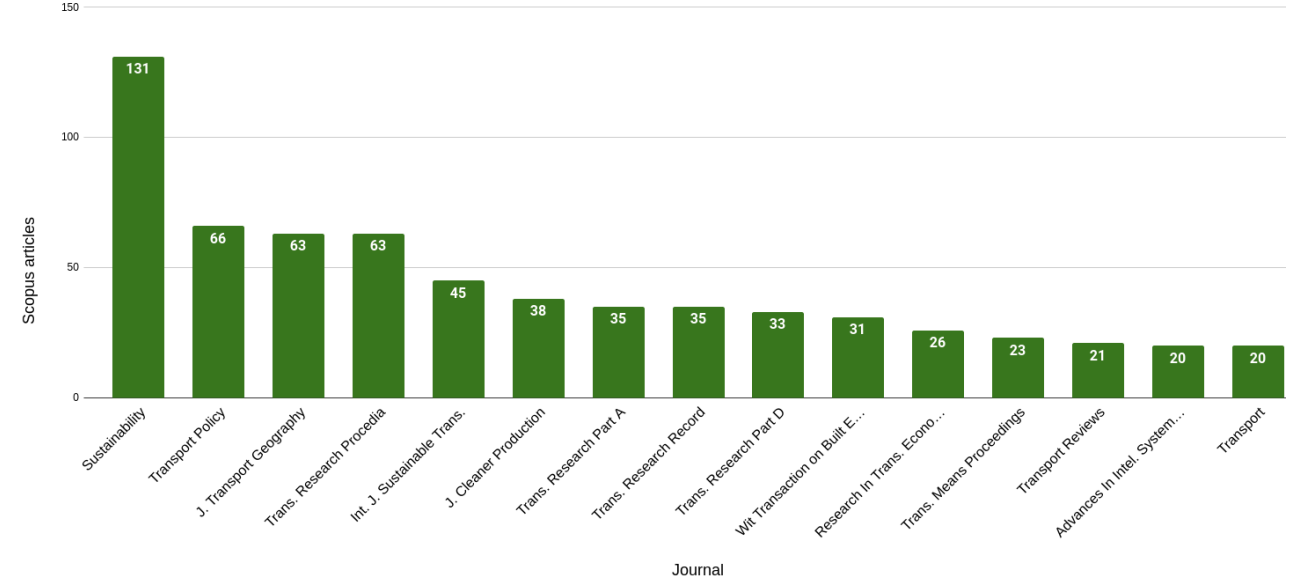

Figure 2. Number of articles published in Scopus-indexed journals on "sustainable transport".

This paper discusses how simulation, optimization, and machine learning could be applied to support managers when making informed decisions while developing Sustainable Transportation Systems. The paper also aims at identifying common challenges, future trends, taxonomy, and insights. The rest of the paper is organized as follows: Section 2 offers a review on Sustainable Transportation Systems (STS). Section 3 analyze applications of optimization in STS. Sections 4-6 discuss how simulation, machine learning, and fuzzy methods have been employed so far in the context of STS. Section 7 identify common challenges, future trends, the taxonomy, and the insights regarding the use of the aforementioned methods in STS. Finally, Section 8 depicts the main conclusions and highlight future work opportunities.

\section{Key Concepts on Sustainable Transportation Systems}

The need for people and goods to be transported across the earth is as old as mankind. Historically speaking, the use of animal thrust (horses, donkeys, etc.) has been associated with the first transportation means. In a parallel way, the use of natural forces (wind, water, etc.) were also implemented. Nevertheless, the industrial revolution, during the eighteenth and nineteenth centuries, involved the development of transportation modes more sophisticated and efficient, e.g., trains or bikes, which provided a more convenient and comfortable way of traveling. Many of these new transportation modes required new technologies, e.g., water steam, to support their continuous development. More recently, the automobile was developed in the twentieth century with the design of the combustion engine. These new devices, built to produce energy which facilitates mobility, involve the release of pollutant elements, smokes, and particles that damage the environment. This indirect effect of releasing pollutant elements associated with mobility is a transportation externality. At the beginning of the industrial revolution, transportation externalities had a low impact on the environment. Nowadays, however, transportation pollutant emissions are the main cause of environmental damage worldwide [10]. This huge industrial development produced by the mankind during the last decades has been caused by the use of non renewable energies, which have fossil origins and offer a limited source due to their exhausting nature. This high impact of transportation activities over nature has urged to control and restrict those emissions. This leads to the concept of sustainable transportation, defined as the transportation whose management, use, and development do not compromise or endanger the future development of next human generations [11]. This way of controlling the transportation is linked to the concept of sustainable development, which was firstly recognized by the 
United Nation's Earth Summit in 1992. This meeting produced an outcome document, called Agenda 21 [12], which highlights the need for designing STS. Existing work on STS key topics are reviewed next.

- Transportation externalities: A first approach to sustainable transportation consist in the selection and measurement of the externalities it generates. There are many transportation externalities, being the release of pollutant particles the most common. Other externalities caused by transportation are: noise, traffic congestion, infrastructure wear, accidents, etc. Thus, by knowing those externalities measurements it is possible to assign them a penalty cost in order to limit the use of transportation modes that have a higher impact on the environment. One of the most popular procedures to estimating this penalty cost is via a proxy monetary value, e.g., the willingness to pay for avoiding one specific transportation externality. This method, called contingent valuation $[13,14]$, searches to elicit the propensity of transportation users to avoid one specific transportation externality by making a payment. This procedure of environmental cost procedure has been revealed very popular in the last years $[15,16]$. Once this cost imputations -due to transportation externalitieshave been estimated, they can be used to: (i) define suitable objective functions in optimization models; or (ii) build specific simulation procedures in order to make decisions. Thus, Serrano-Hernández and Faulin [17] designed a protocol to internalize the costs due to externalities in vehicle routing problems. Furthermore, this type of transportation costs evaluated in willingness-to-pay surveys are extremely connected to the considered geographical areas. Accordingly, Lera-López et al. [18] describes how these estimations can be done in the road freight transportation which crosses the Western Pyrenees, between Spain and France.

- Transportation and environmental issues: Once the environmental impact caused by transportation has been estimated -using, for instance, the contingent valuation method-, we can consider the methodologies that allow us to design the best policies concerning transportation management. Dekker et al. [19] and Bektaş et al. [20] carried out specific literature reviews on the role of Operational Research methods in green logistics and green freight transportation, respectively. Both works depicted the most important problems related to sustainable supply chain management and green mobility. They also shed light in the resolution of practical transportation problems. Applications of these techniques to STS will be reviewed in ulterior sections. Another way to provide support for a more sustainable transportation is the use of green corridors, which are defined as transportation routes that have acceptable environmental characteristics, along with viable economic and logistical attributes [21]. The formal integration of the estimated environmental cost in mathematical models associated with vehicle routing problem was initially performed by Erdoğan and Miller-Hooks [22]. At the same time, Ubeda et al. [23] incorporated penalty costs for emissions release in real-life case studies. After that formal definition of the Green Vehicle Routing Problem (GVRP), many other similar models mushroomed in the scientific literature, as it has been documented in the GVRP literature reviews published by Lin et al. [24], Asghari et al. [25], Moghdani et al. [26], Ren et al. [27], and Patella et al. [28]. The aforementioned literature reviews present the popularity of the sustainable transportation theme in decision-making processes, highlighting an exponential growth in the last five years. Moreover, Sawik et al. [29] made use of multicriteria analysis to face environmental transportation problems. New approaches have been designed to enrich and diversify the ways of tackling the problem in rural and urban road transportation: (i) sharing resources in freight and people mobility; and (ii) design of new non-pollutant vehicles (mainly electric ones, among others). Concerning freight transportation, the use of horizontal cooperation has generated excellent results to mitigate pollutant emissions [30-32]. For instance, the consideration of vehicle routing problems with efficient backhauling strategies can generate important savings in carbon emissions [33,34], thus highlighting the relevance of 
offering alternative routing plans to decision makers [35]. Other type of collaboration in goods distribution is crowd-shipping, which is defined by Archetti et al. [36] as the "use of ordinary people, rather than delivery companies or company employed drivers, to drop-off packages en-route to their destination". Sampaio et al. [37] depicted the dynamics in the crowd-shipping delivery and its imbrication in the urban logistics. McKinnon [38] had already highlighted the benefits associated with this collaboration protocol: it reduces the urban transportation demand, subsidizes the ordinary people trips, and accelerates the delivery operations. Moreover, the collaboration in urban distribution can consider the conjoint use of drones and vans, which can reduce the distribution time improving the service quality [39]. Nevertheless, there is an open debate about the suitability or not of this type of cooperation between air and ground autonomous vehicles in order to mitigate carbon emissions. Kirschstein [40] advocates that for a sustainable remodeling of the system, the most important thing is the primary energy that is used. Therefore, following this line of reasoning, the change to a system with electric and autonomous vehicles can be much more eco-friendly, even if the technology is less energy efficient (provided that the consumption of fossil fuels can be reduced or even replaced by renewable energies). Figliozzi [41] points out that these types of decisions require a general life cycle assessment, which also includes the effects on the manufacture and maintenance of infrastructures. However, governments and legislators must take into account the important changes that may occur specially within the social dimension (i.e., changes in the labor market), supply chains realignments, and the growth of e-commerce centers and dark stores [42].

- City logistics and green logistics: Another important area in sustainable transportation is the design of urban STS both for people and goods. Both freight and people transportation can cause the accumulation of heavy externalities, specially when this activity affects city centers or downtowns. Dealing with these two mobility problems constitutes a great challenge for urban policy makers, and it is closely related to the connected design of smart cities [10]. Barceló [43] analyzes the urban design of future cities. This design decentralizes the need for mobility. Thus, the transportation sustainability could be reached by means of a reduction in demand. Still, other policies are needed in the short run to face the current situation. Considering the problem of urban people mobility, there are two ways to mitigate the impact generated by externalities: (i) the use of big data to transform mobility into smart mobility, rationalizing the number of trips and promoting the use of shared vehicles via the information generated in a smart city [44]; and (ii) making an extensive use of low environmental impact vehicles, mainly electric ones [45]. Finally, Meyer [46] enumerated a long list of actions to decarbonize road freight transportation, as the use of electric vehicles in organized platoons of heavy-duty vehicles.

\section{Applications of Optimization to Sustainable Transportation Systems}

Transportation is one of the early applications of optimization modeling. Most textbooks in Operations Research have a chapter dedicated to transportation problems. The objective of the classical transportation problem is to deliver goods or people, from a set of sources to a set of destinations, in such a way that the transportation cost is minimized. In fact, Bravo and Vidal [47] showed that cost minimization was still dominant at the time when they wrote their review. Since the Kyoto Protocol entered into force in 2005, the pressure for companies to reduce the environmental impact has increased. Likewise, with the adoption of the United Nation Sustainable Development Goals in 2015, the pressure for organizations to be socially responsible has increased as well. These pressures also affect the transportation sector. From the transportation optimization perspective, these pressures are translated into a multi-objective optimization problem, in which the objective functions include environmental and social impact in addition to cost minimization (or profit maximization). In their review, Pérez et al. [48] have observed that the number of optimization studies that take into account environmental and social impact has increased 
in the last years. Optimization has been applied to STS in the form of multi-objective optimization models, in which measures for environmental impact (e.g., greenhouse gas emissions, distance, fuel consumption, vehicle loading, pollution, empty mile) and social impact (e.g., accessibility, reliability, health and safety, congestion) are optimized together with economic measures (e.g., cost and profit). The typical decisions include the use of lower energy transportation modes (efficient energy), the use of inter-modal transportation (e.g., road-rail transportation services for reducing carbon emissions and improving environmental performance), delivery time schedules, sharing delivery routes, improving driving behavior, route optimization, limiting driving speed, regular monitoring of tire inflation, the outsourcing deliveries to third-party logistics, using closer suppliers, and relocating production plants and warehouses. This section will provide an overview of transportation optimization problems using the classification shown in Figure 3.

\begin{tabular}{|lll|}
\hline Urban & Regional/International \\
\hline People & $\begin{array}{l}\text { Urban public } \\
\text { transport, car share, } \\
\text { ride share }\end{array}$ & $\begin{array}{l}\text { Passenger train, } \\
\text { passenger airlines, } \\
\text { ferry }\end{array}$ \\
\hline Goods & City logistics & $\begin{array}{l}\text { Freight, cargo train, air } \\
\text { cargo, sea cargo }\end{array}$ \\
\hline
\end{tabular}

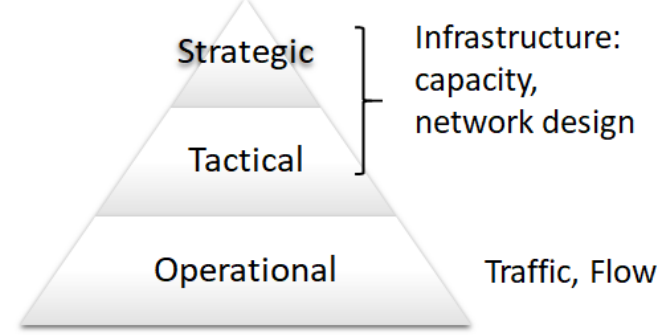

Figure 3. Types of transportation optimization problems.

Based on the size of the area, the application of optimization in STS can be divided into urban transportation systems and regional/global transportation systems. For urban transportation systems, the objective of sustainable transportation is to support the social and economic activities in the city, while reducing the impact on city living conditions (e.g., congestion, emissions, and pollution). For example, Crainic et al. [49] proposed two new problem classes for city logistics and a methodology to address the associated challenges. They argued that consolidation and coordination were the most promising solution that could lead to less freight vehicles traveling within the city and better vehicle loading. Another solution to reduce the number of vehicles traveling into the city is ridesharing initiatives that bring together travelers with similar itineraries and time schedules. Several optimization models that support the matching of riders and drivers in real-time have been proposed by Agatz et al. [50]. The typical objective functions include the total distance, travel time, and number of participants. Vehicle sharing is another solution in which people can rent a vehicle from a provider that offers a network of vehicles located at various depots. The typical decision variables are depot location, allocation of vehicles in each depot, and vehicle redistribution policy [51]. Ride sharing and car sharing services should bring a positive impact to the environment (e.g., reduction in greenhouse gas emission as well as energy consumption) and society (e.g., reduction in pollution and congestion and increased mobility for areas not served by mass transportation system).

Freight transportation is one of the important national/international transportation systems. For example, Liotta et al. [52] considered the environmental impact by developing an optimization model that integrated the production location and freight transportation. Long-haul freight transportation is often combined with other transportation mode (multimodal). The use of multi-modal transportation can reduce greenhouse gas emissions, e.g., by using train for the long distance journey as it is more environmental friendly. In their review, Sun et al. [53] noted that solving a stochastic multi-commodity multi-modal freight routing problem was challenging. Another example of international transportation is shipping. Optimization has also been used to balance between cost and environmental impact of shipping. Ship speed is a key decision variable that affects the cost and the environmental impact of maritime transportation. Hence, optimization has been applied to find the optimum speed at various parts of the journey, as described in the survey by 
Christiansen et al. [54]. Given the high visibility of the airlines industry, the pressure for airlines to reduce its carbon footprint has become stronger. Hence, it is expected that there will be an increase in the application of optimization for sustainable airlines. For example, Tian et al. [55] developed a model that optimizes the speed profile and cruising altitude of a flight by taking into account the environmental impact.

Based on the planning horizon, the application of optimization in STS can be divided into short-term (operational), medium-term (tactical), and long-term (strategic) decisions. For short-term decisions, we typically optimize the traffic flowing through the transportation network, which includes people and goods. The examples cover schedule optimization in city logistics [49], redistribution policies in car sharing services [51], freight routing planning [53] , the use of congestion control [56], or the use of personal mobility carbon allowance [57]. As for the medium and long-term decisions, we typically optimize the design of transportation infrastructure, which includes the design of the transportation network and the location of transportation hubs (e.g., stations, terminals, and depots). Interestingly, Pérez et al. [48] observed that most applications in urban passengers transportation system belong to medium to long-term decisions. Farahani et al. [58] surveyed the application of optimization in the transportation network design. The dominant decision is capacity expansion and the dominant objective is to minimize cost and travel time-which implies minimizing congestion. They noted the need to consider the environmental impact for future studies in this area. In car sharing services, optimization has been used to determine car park locations for pick-up and finish points, as well as their capacities, the charging point locations for those with electric vehicle fleet, and the fleet optimal size [51]. An important development in STS is the increasing support of green vehicles such electric vehicles or hydrogen fuel vehicles by many governments. To promote the use of these vehicles, a good location planning for the refueling or charging stations is important. It is not surprising that optimization has been applied to solve the refueling/charging station location problem (e.g., [59-61]).

Regarding the contents being transported, we have transportation of people, goods, or both. The examples of an optimization model being applied to goods transportation include the papers written by Crainic et al. [49], Sun et al. [53], and Abdullahi et al. [62]. The means to transportation people include public transportation modes (e.g., trains, trams, and buses) as well as private vehicles (e.g., cars, motorcycles, or bikes). An effective public transportation system should have a positive effect on environmental impact (e.g., less fuel and less gas emissions) and social impact (e.g., less congestion and better accessibility). Optimization has been used to design efficient public transportation systems [63]. Recently, there has been an increase in the application of optimization in collaborative use of vehicles. for example, car sharing services [48] and ride sharing services [50]. While the main purpose of car sharing is to move people from one location to another, cars need to be redistributed regularly to various car stations to meet the expected demands in various locations at different times. Hence, in car sharing services, both people and goods are transported. Table 1 summarizes the concepts and examples discussed in this section.

Modern infrastructure for transportation systems support real-time communication systems (e.g., vehicle-to-vehicle and vehicle-infrastructure) and generate real-time data on congestion, accidents, traffic light malfunction, etc. As more modern transportation infrastructure are being developed and used, the application of a real time simulation-optimization method such as the one introduced in Onggo et al. [64] will become more prevalent. 
Table 1. Sustainable Transportation Systems (STS) optimization concepts and their examples.

\begin{tabular}{cc}
\hline Concept & Examples \\
\hline Urban transportation-city logistics & Crainic et al. [49] \\
Urban transportation-ride share & Agatz et al. [50] \\
Urban transportation-car share & Ferrero et al. [51] \\
National/international transportation-freight & Liotta et al. [52], Sun et al. [53] \\
National/international transportation-maritime & Christiansen et al. [54] \\
National/international transportation-airlines & Tian et al. [55] \\
Short-term decision & Crainic et al. [49], Ferrero et al. [51], Sun et al. [53], \\
& Yin and Lawphongpanich [56], Aziz et al. [57] \\
Medium-long term decision & Pérez et al. [48], Farahani et al. [58], Ferrero et al. [51], \\
Passengers transportation & Miralinaghi et al. [59], Cavadas et al. [60], Kim and Kuby [61] \\
Goods transportation & Yang et al. [63], Pérez et al. [48], Agatz et al. [50] \\
& Crainic et al. [49], Sun et al. [53], Abdullahi et al. [62] \\
\hline
\end{tabular}

\section{Applications of Simulation to Sustainable Transportation Systems}

Simulation is an invaluable tool for modeling stochastic and/or systems that evolve over time. Because of its ability to represent real-life scenarios, simulation has been used to support decision making in transportation systems. Simulation is a powerful technique since it allows us to make changes in the system and test their impact without making those changes in the real system. This flexibility further allows one to include the three dimensions of sustainability (i.e., economic, environmental, and social) into the decision making process and evaluate how some actions may impact those dimensions. The economical dimension focuses on the cost and it has been the main focus of many simulation studies dealing with STS. The environmental dimension concerns issues including pollution, climate changes, and energy consumption. The social dimension includes labor psychology and aging workforce. Simulation studies with sustainability concerns in transportation and logistics have mostly focused on the economic and environmental dimensions with the goal of reducing energy consumption [65]. Table 2 classifies the papers covered in this section according to their focus on sustainability pillars. While many of the studies focus on sustainability explicitly (for example, by reducing the $\mathrm{CO}_{2}$ emissions), there are studies that achieve sustainability implicitly (by timing the traffic lights so that the wait time is reduced and hence the greenhouse gas emissions).

Table 2. Sustainability pillars studied in STS simulation papers.

\begin{tabular}{cc}
\hline Sustainability Pillars & Examples \\
\hline Environmental & Benzaman et al. [66], Pruckner and German [67], \\
Economical & Jordan [71] \\
Both & Danloup et al. [72], Hoffa-Dabrowska and Grzybowska [73], Rabe et al. [74], \\
& Van Der Vorst et al. [75], Lokhandwala and Cai [76] \\
\hline
\end{tabular}

Several simulation technologies have been applied for decision making in STS. Karakikes and Nathanail [77] provide a review of simulation methods used for sustainable urban transportation. Among the methods that we would like to emphasize are Monte-Carlo simulation, discrete-event simulation, system dynamics, and agent-based simulation. Monte-Carlo simulation, which is the simplest simulation technique, is used when there is randomness in the system but no change over time. Discrete-event simulation is used when the system evolves over time. The system changes its status based on the events that happen at certain times. Zhou and Kuhl [78] develop a sustainability toolkit for discrete-event simulations that could produce sustainability related performance measures. System dynamics focus on longer time horizons where the dynamics of the system is described in a quasicontinuous way [79]. Finally, agent-based simulation models 
simulate the interactions of autonomous agents to understand their impacts on the entire process. These models have been particularly used in the sustainable dynamic transportation systems, where agents may take the form of dynamic transportation vehicles, drivers, passengers, or dispatchers [80].

Simulation is an indispensable tool for "what-if" analysis. However, it cannot be used as an optimization technique. As discussed in Section 3, optimization techniques play an important role in the management of transportation systems. Therefore, combining simulation and optimization has been a growing research area. Different approaches have been proposed to combine simulation and optimization [65]. Among them, simheuristic approaches, which integrate simulation within metaheuristics, have been found to be promising [81]. The success of simheuristics has been boosted by computational advancements and extensive research on how to speed up those procedures [82]. In the remainder of this section, we review some exemplary studies that use various simulation techniques and possibly simulation-optimization as a tool to design and operate STS. Figure 4 provides an overview of the three application areas discussed in this section along with their objectives and simulation methodologies used.

Logistics Operations in Food Supply Chains

Goal: Investigate how cooperation and supply chain network structure impact sustainability pillars Methodologies/Software Used: Discrete-event simulation, ALADIN, SimChain

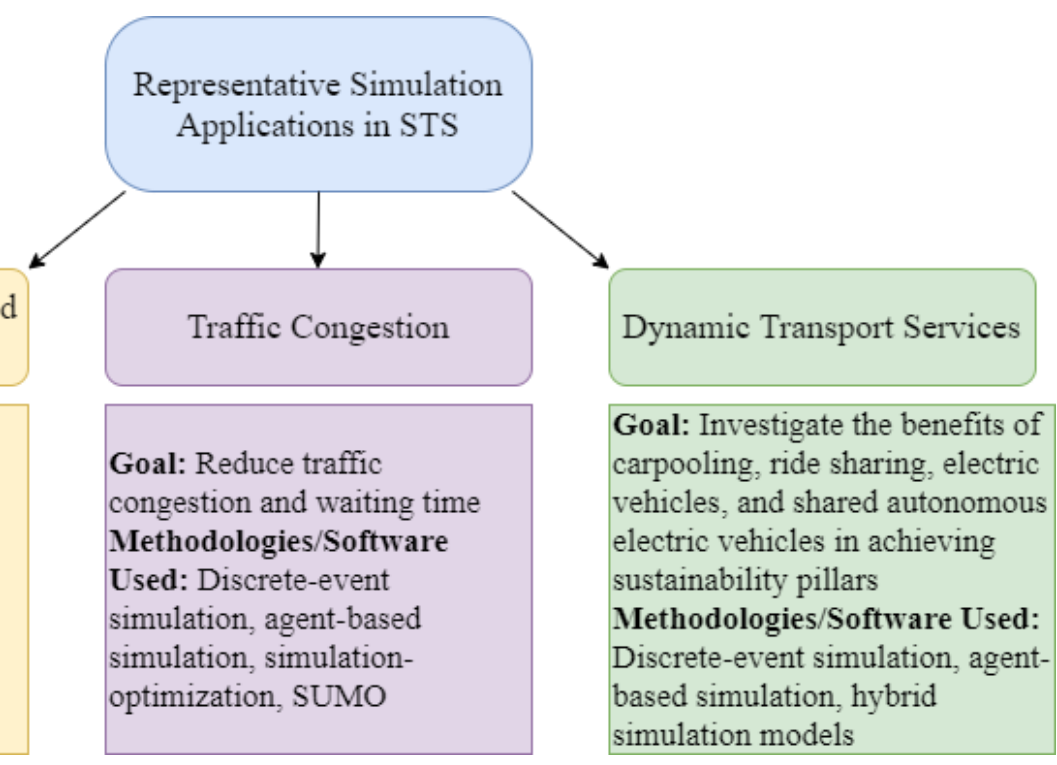

Figure 4. Applications of Simulation Techniques to STS.

- $\quad$ Logistics operations in sustainable food supply chains: Research in this area has mainly focused on how cooperation among supply chain members and how the supply chain network structure help sustainability efforts. For example, Danloup et al. [72] study the environmental impact of collaborative food distribution in food retail services. Through a case study that simulates the logistics network of a British distributor of fruits and vegetables, authors show that sharing trucks between retailers help sustainability efforts in terms of reducing $\mathrm{CO}_{2}$ emissions and transportation costs. Recently, Hoffa-Dabrowska and Grzybowska [73] develop a simulation model of a supply chain to show how consolidation of transportation orders help the economical and environmental pillars of sustainability. In another study, Rabe et al. [74] use a supply chain simulation tool called SimChain [83] to compare two different supply chain network structures in terms of their costs and $\mathrm{CO}_{2}$ emissions. In the context of food supply chains, Van Der Vorst et al. [75] introduce a new discrete-event simulation tool, which takes into account food quality change and logistics related to it as well as sustainability indicators into the simulation study.

- Traffic Congestion: Traffic congestion is one of the main challenges faced by large metropolitan areas and it has numerous impacts on sustainability pillars including contributing to $\mathrm{CO}_{2}$ emissions. Therefore, it is important to decrease vehicles' travel 
time on the roads and hence decrease environmental pollution. Below we review studies that aim to decrease vehicles' travel time by developing a centralized route management system and by the appropriate timing of traffic lights:

- Centralized Route Management: Simulation is a very useful tool to model and analyze traffic conditions in a city. One of the inputs to the simulation is the traffic patterns and flows that are fed to the simulation in the form of O-D (origin-destination) matrix. Obtaining the O-D matrix in some cities could be a challenge. Focusing on Valencia, Spain, Zambrano et al. [84] generate an O-D matrix as an approximation to the real traffic distribution in this area. Authors rely on DFROUTER tool [85] to achieve the desired O-D matrix. DFROUTER is a package included in SUMO [86], which is a simulation platform that allows one to perform traffic simulation by microscopic modeling of cities and vehicles. Building on this work, Zambrano-Martinez et al. [87] developed a centralized route manager for autonomous vehicles that can optimize traffic flows while taking into account the present and future traffic conditions. With the increasing popularity of autonomous vehicles, congestion problems might be more common in the near future. The focus on autonomous vehicles also allows for more predictive behavior on the road. Authors showed that their proposed model was able to improve travel times and average travel speed in Valencia, Spain by $5 \%$. In more congested areas, this improvement was about $8 \%$.

- $\quad$ Traffic light timing: The problem of timing of traffic lights has been studied with simulation for a long time. This is one of the areas where sustainability benefits are offered implicitly. Because strategic timing of lights reduce traffic as well as waiting time- - and hence gas emissions-, two sustainability pillars (cost reduction and gas emission reduction) are achieved automatically. Patel et al. [88] study the problem of signal control for pre-timed junctions, and propose a simulationoptimization approach that identifies the optimal green times in order to minimize the average delay per vehicle. Using an agent-based simulation model, Li et al. [89] investigate how the information from connected vehicles could be used so that optimal traffic signal control can be obtained at intersections. These authors show that potential system average time savings and traffic queue length reduction can be achieved. Through a discrete-event simulation model, Benzaman et al. [66] show that factors like synchronization of traffic lights, route configuration, or dispatch time and pattern of vehicles can have significant impact on $\mathrm{CO}_{2}$ emissions. Vehicle-to-vehicle and vehicle-to-infrastructure communication are two approaches that was shown to work well for eliminating traffic congestion. Benzaman and Sharma [90] develop a discrete-event simulation model that integrates these two approaches. Results show that the vehicle-toinfrastructure model enjoyed benefits including reduced waiting time and system time.

- Dynamic, demand-based transportation services: Bischoff and Maciejewski [80] present an excellent review on the emerging dynamic, on-demand transportation modes, and their impact on sustainability efforts. These new transportation modes can help enhance overall sustainability efforts by reducing private car use and through more efficient dispatch strategies. Among the most popular services are carpooling and ride sharing. Thus, for instance, Fikar et al. [91] propose a simulation-based heuristic to reduce the number of vehicles employed during home healthcare services. With fewer cars on the road, less empty seats, and less vehicle ownership, these services could contribute to sustainability efforts. The use of simulation to study the impact of car sharing goes back to the 1970s. Lokhandwala and Cai [76] develop an agent-based simulation model in the context of taxi ride-sharing problem in New York City with the objectives of decreasing the fleet size, increasing the occupancy rate, decreasing the total travel distance, and reducing the carbon emissions. Authors find that ride sharing reduces carbon emissions up to 866 metric tonnes per 
day. Alonso-Mora et al. [92] present a general framework for real-time high-capacity ride sharing with sustainability considerations. Simulation is utilized to represent scenarios with dynamic demand and vehicle locations. The use of electric vehicles in taxi fleets presents another opportunity to reduce local emissions in urban transport. There are several studies conducted in different cities and regions to study the impact of electric cars. For example, Pruckner and German [67] use a simulation model to study the impact of electric vehicles on the energy system of Germany. Authors find that electric vehicles play a role in the reduction of $\mathrm{CO}_{2}$ emissions. Building on the simulation model designed by Pruckner and German [67], Doluweera et al. [68] develop a hybrid simulation model (combining system dynamics with discrete-event simulation) to investigate the benefits of electric vehicles in Alberta, Canada. The results show that electric vehicles can decrease the Alberta greenhouse gas emissions significantly. Similarly, Longo et al. [93] show that the usage of electric cars in Italy provide approximately $30 \%$ reduction in $\mathrm{CO}_{2}$ emissions. Another emerging area that would help with sustainability efforts in urban areas is the use of shared autonomous electric vehicles. Narayanan et al. [94] provide a comprehensive review of shared autonomous vehicles and their uses. Jordan [71] develop an agent-based simulation model to study the cost impact of shared autonomous vehicles. Fagnant and Kockelman [69] focus on the environmental benefits of shared autonomous vehicles and find that reductions in energy consumption, gas emissions, and air pollutants emissions are possible. Recently, Dlugosch et al. [70] show that autonomous electric vehicles can enable zero-emission urban mobility by reducing the fleet size.

\section{Applications of Machine Learning to Sustainable Transportation Systems}

An overview of machine learning and data science concepts in the context of transportation analytics and STS can be found in Antoniou et al. [95]. This manuscript also contains different examples of applications, among others: traffic simulation models to identify mobility patterns, human mobility patterns across cities, and transit data analytics.

In the context of machine learning applications in urban mobility research, Zhou et al. [96] make use of a random forest model to investigate citizens' patterns when choosing between a bike-sharing transportation system or a taxi transportation system. In order to do so, they analyze data from the city of Chicago. Their results show the existence of a seasonal component in the demand for bike-sharing transportation and a declining trend in the use of taxi services. Also in the context of urban mobility, Yang et al. [97] propose the utilization of graph-based features and deep neural networks to forecast demand patterns in the short term, thus supporting a more efficient organization of bike-sharing systems. Yet related to bike-sharing systems, Zhou et al. [98] propose the use of random forest classification to support managers' decision making on the appropriate number of bicycles in each city area. Based on data from Singapore, Basu and Ferreira [99] study the variables that conditionate the private ownership of vehicles. They used a combination of neural networks and logit regression to identify the factors that influence citizens' decision about vehicle ownership, including: existence of an efficient public transportation system, age, gender, income and job sector, taxi services, etc. In the context of the Palermo city, Migliore et al. [100] propose a demand-based optimization model, and a solving heuristic, for efficient parking pricing. The model aims at balancing the different transportation modes in the city, from private cars to public buses. Ali Khalil et al. [101] make use of different machine learning methods to predict noise levels in roadways. These methods included decision trees, support vector machine, ensembles, and neural network. According to the authors, some of these machine learning models were able to outperform a regression model that was previously developed for predicting traffic noise in a United Arab Emirates city. Tang et al. [102] propose a machine learning method, based on the gradient boosting decision tree algorithm, to predict the unboarding stops of city bus passengers from data recorded in passengers' smart cards, which typically contain the boarding stop alone. Having a better knowledge of the estimated passengers' flows is relevant to improve the planning and operations of 
the bus system and, therefore, its long-term sustainability. In the context of sustainable smart cities, Majumdar et al. [103] combine data provided by internet of things devices and machine learning methods (long short-term memory networks and other multivariate predictive models) to forecast the evolution of traffic congestion during the next few minutes. Based on data collected in Milan, Liang et al. [104] utilize multinomial logit, random forest, and support vector machine models to study household travel mode choice based on factors such as vehicle ownership, travel distance, travel time, etc. With their crowdsourcing concept, Giret et al. [105] propose to use the 'regular' trips performed by citizens to support last mile delivery. In that way, when citizens move following their own needs, they also become ad hoc deliverers. For that purpose, they make use of multi-agent system techniques and network-based algorithms designed to optimize delivery routes.

According to Hasan et al. [106], the use of autonomous vehicles using 'green' energy sources, and employing artificial intelligence algorithms, could reduce pollutant emissions in about $80 \%$ or more. From their review of the recent literature, these authors also conclude that an efficient combination of environmentally friendly public transportation and ride-sharing practices can contribute to a significant reduction in both traffic congestion and environmental impact. Nandal et al. [107] study how neural networks can be used in transportation engineering, including a discussion on both benefits and disadvantages. The authors also highlight the role of neural networks in planning maintenance activities that contribute to limit the deterioration of the public road infrastructure. In order to contribute to identify challenges in the growing use of electric vehicles in the USA, Asensio et al. [108] use supervised machine learning methods to analyze text reviews provided by users of over 12,000 charging stations. Their findings suggest that private and public charging locations offer a similar quality to users, and that there are still some issues that need to be improved in order to expand this mode of sustainable transport. Finally, Consilvio et al. [109] discuss the utilization of machine learning methods in railway asset management.

Figure 5 shows, in a visual manner, how the different machine learning techniques have been applied in STS. One can notice that neural networks and decision trees have been repeatedly employed for predicting purposes, that heuristics are mainly used to achieve efficient performance in the design of routing plans involving autonomous vehicles as well as in pricing, and that analyzing citizens' patterns and transportation modes have been the target of different machine learning methods.

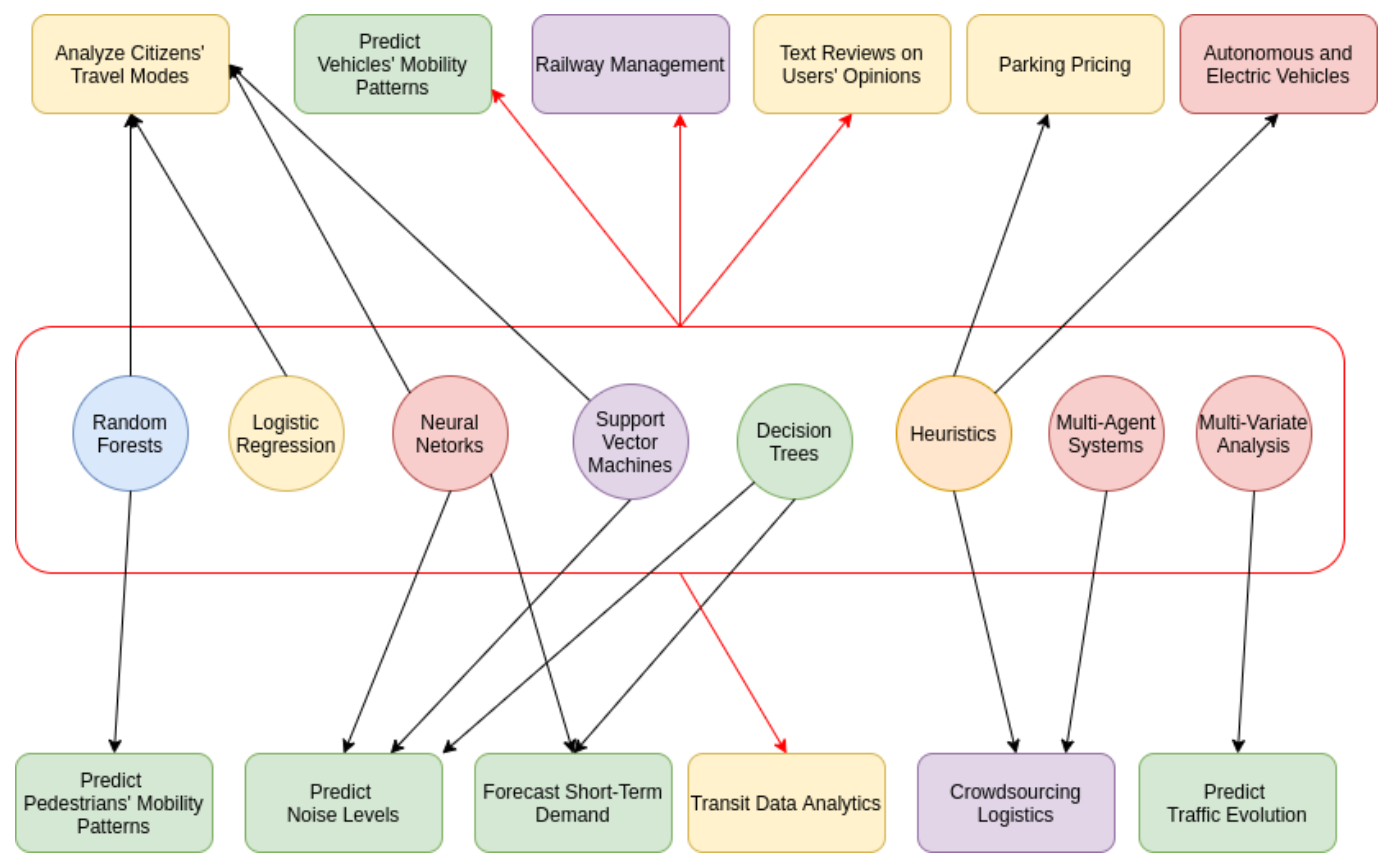

Figure 5. Applications of machine learning techniques to STS. 


\section{Applications of Fuzzy Sets to Sustainable Transportation Systems}

In the context of the oil transportation industry, Dimić et al. [110] propose a fuzzybased methodology that allows managers to promote sustainable transportation strategies based on objective criteria. Their methodology combines the fuzzy Delphi method with a typical strengths-weaknesses-opportunities-threats analysis. Mohagheghi et al. [111] apply fuzzy sets to tackle the problem of selecting a portfolio of sustainable transportation projects. In particular, these authors develop a case study in which they use interval-valued fuzzy sets to model the uncertainty associated with the investment process, and combine both the opinion of experts with the considerations made by decision makers. In the context of the transportation sector, Ülengin et al. [112] utilize a fuzzy cognitive map analysis, which relies upon expert opinions and a survey, to identify the main factors influencing on the environment and their inter-dependencies. According to de Paula and Marins [113], algorithms based on fuzzy logic have not been show their full potential yet when addressing sustainability problems in transportation systems. These authors consider that fuzzy logic models can support policy makers worldwide to design city transportation systems with a lower level of emissions. In order to contribute to reduce traffic congestion in highways, Zhang et al. [114] propose a traffic prediction system based on a hierarchical fuzzy rule-based system. The fuzzy system is optimized by means of a genetic algorithm. The proposed approach is then tested using several benchmarks, and compared with other existing algorithms. With the goal of evaluating several efficiency and sustainability indicators in urban bus transportation systems, Jasti and Ram [115] employ fuzzy logic to deal with the uncertainties that arise in real-life applications. In a road-rail multimodal transportation network, Sun et al. [116] study the vehicle routing problem with hazardous materials. Here, the goal is to minimize the total risk of all transportation actions. These authors employ fuzzy programming to model the uncertainty in the number of citizens exposed to the risk. Tadić et al. [117] proposes a fuzzy-based methodology that allows for prioritizing the characteristics of new inter modal terminals. Among these characteristics, sustainability dimensions as well as the needs of different stakeholders are considered. A case study in Serbia contributes to illustrate the concepts. Similarly, Haider et al. [118] make use of a methodology based on fuzzy set to identify and analyze barriers to the adoption of electric vehicles in India. According to their findings, the main barriers are due to: limited power availability, driving-range constraints due to a limited battery life, and lack of a charging infrastructure. Thus, Kaya and Erginel [119] proposed a hybrid fuzzy method that, according to the authors, allow to enhance the sustainable level of airports while taking into account dimensions such as passengers' and managers' sustainability requirements. In the context of travel chains, Kisgyörgy and Tóth [120] introduce a method that allows policy makers to study and optimize the service quality. Their method uses several dimensions to measure the travel comfort, and then employs a fuzzy-based approach to provide a global score of the comfort conditions along the travel chain. A case study in Budapest is utilized to illustrate the proposed concepts.

At this manner, based on a case study involving electric bikes, Shekhovtsov et al. [121] propose two methods to study how some decision criteria might impact on STS. Their analysis is based on fuzzy-related multi criteria decision analysis methods. Zagorskas and Turskis [122] proposes a fuzzy-based methodology that allows policy makers to rank the priorities for development and renewal of bicycle pathway segments. Based on a case study in a large Indian city, Singh et al. [123] introduce a framework for the selection of sustainable transport. Different transportation alternatives are considered: state-run bus, pooled car, and private buses. Among the criteria employed to select the transportation mode, the authors highlight the following ones: $\mathrm{CO}_{2}$ emissions, cost of fuel, energy efficiency, cost of maintenance, number of accidents, congestion, number of injuries, and road noise. In order to prioritize the criteria, a fuzzy version of the analytic hierarchy process is employed. Moreover, Watróbski et al. [124] make use of different multi-criteria analysis methods, some of which employ fuzzy techniques to account for uncertainty elements, in order to study how the use of electric vehicles can contribute to enhance the sustainability 
level of urban last-mile delivery actions. In the context of electric vehicles, Tsang et al. [125] propose a fuzzy-based method to predict the battery life-cycle, thus promoting the effective use of this sustainable transportation mode.

To model the perceived utility of transportation systems, Cantarella and Fedele [126] employs fuzzy numbers instead of the more traditional random variables. In a similar line, Ramazani et al. [127] discuss the idea that drivers' perception of travel times vary even for the same route. Hence, they make use of fuzzy set theory to model drivers' perceptions and present a traffic assignment algorithm that employs these perceptions on travel times. Their algorithm is used then to estimate traffic flows, showing promising results when compared with already existing approaches. Likewise, Miralinaghi et al. [128] introduce a fuzzy-based traffic assignment model. The model is tested in small-, medium-, and large-sized networks. According to the authors, their model can provide a more accurate estimate of the traffic volume in cities. Finally, Miralinaghi et al. [129] proposes to model users' perceptions of travel times as fuzzy sets. The authors show that their model can be efficiently solved even when considering large-scale transportation systems.

Figure 6 illustrates the main applications of fuzzy techniques in the field of STS. Notice that these applications are quite diverse. While some of them focus on different aspects related to the use of electric vehicles, others are more centered towards infrastructure design and maintenance. Yet, other applications aim at supporting travelers' while selecting a customized, comfortable, and environmentally friendly transportation mode.

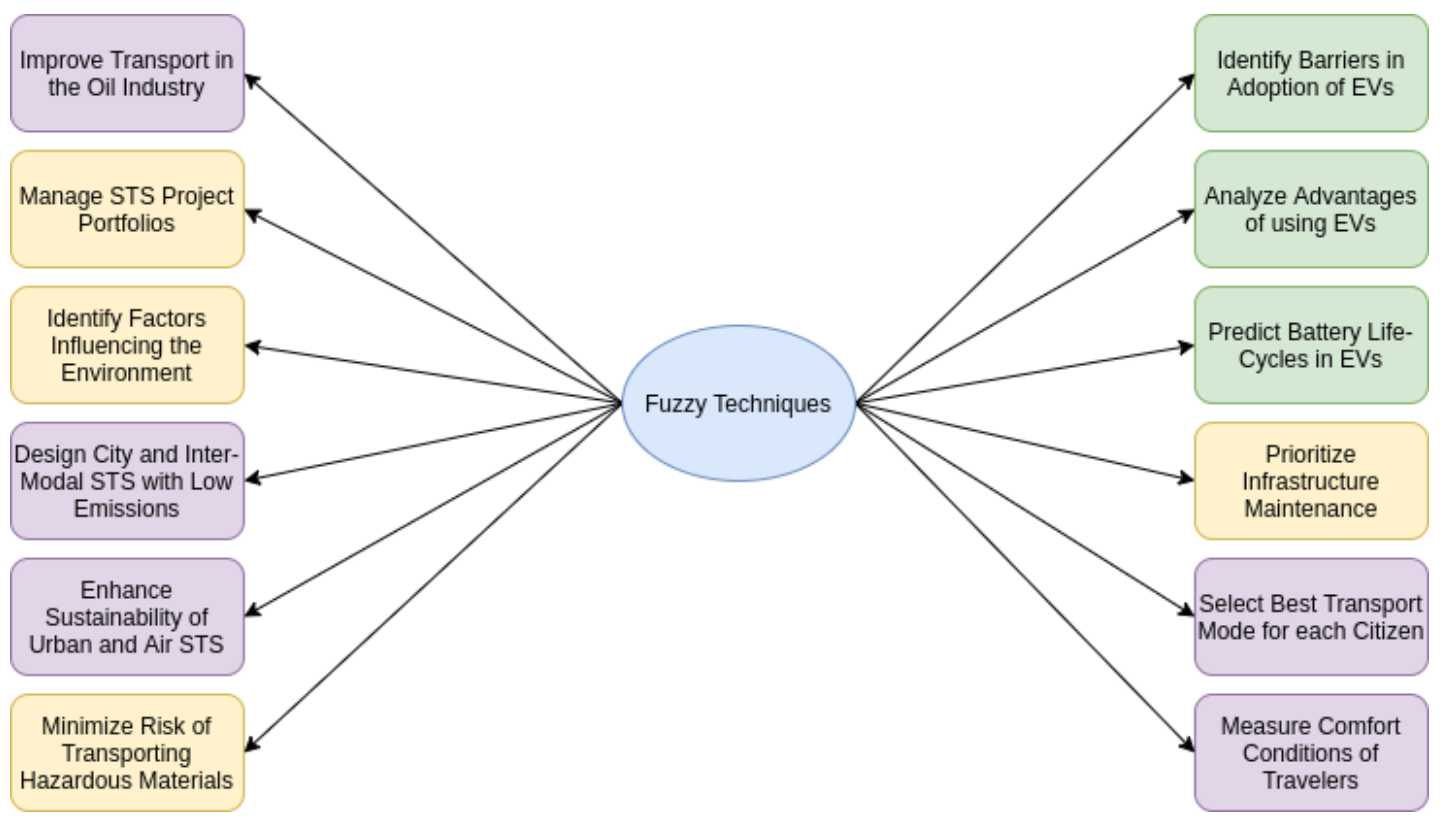

Figure 6. Applications of Machine Learning Techniques to STS.

\section{Common Challenges and Future Trends}

The complex sustainability problems that arise today demand a paradigm shift in the way of doing business. Hence, they require an expansion of criteria considering not only economic aspects, but also environmental and social criteria. The methodologies and techniques analyzed in Sections 2-6 demonstrate the prioritization of sustainability-oriented innovation initiatives. Their conception and design is intended to serve as a support in the decision-making process in order to meet the economic competitive advantage required in modern transportation systems, while meeting several social and environmental goals. However, it is necessary to overcome a series of technical difficulties and to change social consumption habits $[130,131]$. It is in this context where the differentiation of the problems and techniques/methodologies used according to a time horizon makes more sense. Thus, this section aims to collect and classify, from a management perspective, 
the different decisions that can be made, as well as the problems associated to each level of the decision pyramid.

The strategic level is where the activities of top managers are developed. This includes the strategic objectives that will have a long-term influence. Among them, sustainability, impact, and environmental objectives, which serve as a framework for lower-level planning [132,133]. These refer to the development of the basic framework that serves to create awareness about sustainability, risks, and opportunities for improvement, considering the level of technology and the degree of knowledge and population involvement. Among them, the following stand out: the design of evaluation protocols as described in Serrano-Hernández and Faulin [17], the design and optimization of infrastructures (these can be new or an adaptation of the existing ones) [48], demand forecasting with machine learning methods [95], or population behavior analysis with simulation methods in order to evaluate future changes [79]. Hence, governments and companies will be able to use these methodologies to assess the scope and viability of their objectives. However, and to the best of our knowledge, the possibilities of exploitation and applicability of the methodologies described in this paper have not yet reached their maximum potential in this decision level. Many of the changes, adaptations and improvements that have been established are limited to lower levels, when it is at this level that changes in sustainability would imply a substantial impact.

More importantly, as governments and companies begin to considerate and integrate in their strategies global competition for resources and promulgate and face more environmental regulations, the focus has moved beyond the consideration of whether or not it pays off to be environmentally friendly to focus on how to address environmental challenges while maintaining competitiveness and social awareness [134]. Here is where tactical decisions take on increasing importance. In this medium-term level, the available resources are assigned and optimized (for example, costs, human resources, or vehicle fleets) to achieve the strategic objectives set in the previous stage. In addition, guidelines for the lower decision level are included for operations managers. Examples of the applicability of the studied methodologies would be the analysis of cost and time reduction derived from the use of inter-modal transportation models, or the optimization of existing transportation infrastructure and chains [58]. It is also possible to investigate the benefits of changing the vehicle fleet by simulation techniques $[72,80,106]$. However, it is necessary for governments and companies to know and recognize the benefits of quantitative changes [135], and to promote the use of these methodologies as support tools that can help establish a new framework towards total sustainability.

In the operational level is where decisions with a short-term effect take place. It is at this level that most of the analyzed works of all the methodologies presented are developed, since it allows implementing improvement, change, and optimization actions of quick impact with the available resources. Sustainability generates new business and improvement opportunities through innovation that enables competitive improvements [72,88]. Thanks to these improvements at the operational level, many companies will obtain the ultimate benefits of market opportunities and efficient business operations, some of them with a lower investment than the expected one. Furthermore, these methodologies can allow for discovering, specifying and systematizing appropriate areas of action [136]. However, many of the companies that want to work in a sustainable environment need a holistic vision to achieve it. This requires a comprehensive framework that shows the perspective of sustainability, which is not always available to everyone [135]. Thus, one of the challenges to overcome is the dispersion of the optimization and improvement resources and the knowledge necessary to be able to apply them properly.

\section{Conclusions and Future Work}

In the context of Sustainable Transportation Systems (STS), this paper has reviewed some of the most popular methods for their analysis and enhancement. Among these, we have discussed the use of optimization and simulation models, machine learning 
methods, and fuzzy techniques. Optimization and simulation have been around longer than machine learning and fuzzy method. Hence, it is not surprising that simulation and optimization models are the more dominant methods in STS research. However, in recent years,machine learning and fuzzy methods are gaining popularity in STS research.

Given the complexity of STS that take into consideration economic, social and environmental sustainability factors, it is unlikely that a single method is sufficient to meet the challenge in STS. Hence, a hybrid model is needed [137]. For example, we can combine simulation with fuzzy and optimization methods (e.g., simheuristics [138]), optimization and machine learning methods (e.g., learnheuristics [139], etc., to efficiently tackle many of the challenges raised by STS. Some of these challenges refer to the effective introduction of zero-emission transportation methods, which include autonomous electric vehicles and bikes, as well as the increasing popularity of the more sustainable transportation modes that minimize the energy consumption and environmental impact caused by single-user trips and empty backhauling practices. In the case of the former, the increasing incorporation of ride-sharing, car-pooling, and car-sharing mobility policies can lead to more efficient and STS, specially in urban contexts. For the latter, the incorporation of horizontal cooperation strategies [30] might be a key factor in long-distance transportation practices.

Modern infrastructure for transportation systems support real-time communication systems and generate real-time data using Internet of Things. This enables the application of a real time simulation-optimization method. Onggo et al. [64] have proposed a hybrid model that support real-time decision making. As future research lines, we would like to extend the work done by Onggo et al. [64] to: (i) fully integrate the Internet of Things concept with STS, specially in urban areas, where a large amount of data might be provided in real time by different sensors and recording devices; (ii) develop the digital twins (e.g., real-time simulators) that allow policy makers to make data-driven strategic, tactical, and operational decisions; and (iii) develop hybrid methods that allow us to define strategic and tactical decisions, and 'agile' methods that allow us to process data in real time and make fast, yet efficient, operational decisions in a dynamic and complex urban environments.

Author Contributions: Conceptualization, A.A.J. and J.F.; methodology, C.G.C., R.d.I.T. and B.S.O.; writing—original draft preparation, C.G.C., R.d.I.T. and B.S.O.; writing—review and editing, A.A.J. and J.F. All authors have read and agreed to the published version of the manuscript.

Funding: This work has been partially supported by the Spanish Ministry of Science, Innovation, and Universities (PID2019-111100RB-C21-C22/AEI/10.13039/501100011033, RED2018-102642-T) and the SEPIE Erasmus+ Program (2019-I-ES01-KA103-062602), and the IoF2020-H2020 (731884) project.

Conflicts of Interest: The authors declare no conflict of interest.

\section{References}

1. United Nations. Transforming Our World: The 2030 Agenda for Sustainable Development; Division for Sustainable Development Goals: New York, NY, USA, 2015.

2. McCollum, D.L.; Krey, V.; Riahi, K.; Kolp, P.; Grubler, A.; Makowski, M.; Nakicenovic, N. Climate policies can help resolve energy security and air pollution challenges. Clim. Chang. 2013, 119, 479-494. [CrossRef]

3. Erickson, L.E.; Jennings, M. Energy, transportation, air quality, climate change, health nexus: Sustainable energy is good for our health. AIMS Public Health 2017, 4, 47. [CrossRef] [PubMed]

4. Mihyeon Jeon, C.; Amekudzi, A. Addressing sustainability in transportation systems: Definitions, indicators, and metrics. J. Infrastruct. Syst. 2005, 11, 31-50. [CrossRef]

5. Fiksel, J. Sustainability and resilience: Toward a systems approach. Sustain. Sci. Pract. Policy 2006, 2, 14-21. [CrossRef]

6. Weichenthal, S.; Farrell, W.; Goldberg, M.; Joseph, L.; Hatzopoulou, M. Characterizing the impact of traffic and the built environment on near-road ultrafine particle and black carbon concentrations. Environ. Res. 2014, 132, 305-310. [CrossRef] [PubMed]

7. Lopez-Arboleda, E.; Sarmiento, A.T.; Cardenas, L.M. Systemic approach for integration of sustainability in evaluation of public policies for adoption of electric vehicles. Syst. Pract. Action Res. 2020. [CrossRef]

8. Li, H.; Wang, Y.; Yan, H.; Fang, Y. Prioritizing social sustainability indicators of public projects: A Chinese context. In Proceedings of the ICCREM 2017, Guangzhou, China, 10-12 November 2017; pp. 120-127. 
9. Liu, X.; Gao, L.; Ni, A.; Ye, N. Understanding better the influential factors of commuters' multi-day travel behavior: Evidence from Shanghai, China. Sustainability 2020, 12, 376. [CrossRef]

10. Faulin, J.; Grasman, S.E.; Juan, A.A.; Hirsch, P. Sustainable Transportation: Concepts and Current Practices. In Sustainable Transportation and Smart Logistics; Elsevier: Amsterdam, The Netherlands, 2019; pp. 3-23.

11. McKinnon, A.; Browne, M.; Whiteing, A.; Piecyk, M. Green logistics: Improving the Environmental Sustainability of Logistics; Kogan Page Publishers: London, UK, 2015.

12. Lafferty, W.M.; Eckerberg, K. From the Earth Summit to Local Agenda 21: Working towards Sustainable Development; Routledge: Abingdon-on-Thames, UK, 2013.

13. Hensher, D.A.; Button, K.J. Handbook of Transport and the Environment; Elsevier: Amsterdam, The Netherlands, 2003 ; Volume 4.

14. Sánchez, M.; López-Mosquera, N.; Lera-López, F.; Faulin, J. An extended planned behavior model to explain the willingness to pay to reduce noise pollution in road transportation. J. Clean. Prod. 2018, 177, 144-154. [CrossRef]

15. Lera-López, F.; Faulin, J.; Sánchez, M. Determinants of the willingness-to-pay for reducing the environmental impacts of road transportation. Transp. Res. Part D Transp. Environ. 2012, 17, 215-220. [CrossRef]

16. Denant-Boèmont, L.; Faulin, J.; Hammiche, S.; Serrano-Hernandez, A. Managing transportation externalities in the Pyrenees region: Measuring the willingness-to-pay for road freight noise reduction using an experimental auction mechanism. J. Clean. Prod. 2018, 202, 631-641. [CrossRef]

17. Serrano-Hernández, A.; Faulin, J. Internalizing negative externalities in vehicle routing problems through green taxes and green tolls. SORT 2019, 1, 75-94.

18. Lera-López, F.; Sánchez, M.; Faulin, J.; Cacciolatti, L. Rural environment stakeholders and policy making: Willingness to pay to reduce road transportation pollution impact in the Western Pyrenees. Transp. Res. Part D Transp. Environ. 2014, 32, 129-142. [CrossRef]

19. Dekker, R.; Bloemhof, J.; Mallidis, I. Operations Research for green logistics-An overview of aspects, issues, contributions and challenges. Eur. J. Oper. Res. 2012, 219, 671-679. [CrossRef]

20. Bektaş, T.; Ehmke, J.F.; Psaraftis, H.N.; Puchinger, J. The role of operational research in green freight transportation. Eur. J. Oper. Res. 2019, 274, 807-823. [CrossRef]

21. Panagakos, G. Green corridors basics. In Green Transportation Logistics; Springer: Berlin/Heidelberg, Germany, 2016 ; pp. 81-121.

22. Erdoğan, S.; Miller-Hooks, E. A green vehicle routing problem. Transp. Res. Part E Logist. Transp. Rev. 2012, 48, 100-114. [CrossRef]

23. Ubeda, S.; Arcelus, F.J.; Faulin, J. Green logistics at Eroski: A case study. Int. J. Prod. Econ. 2011, 131, 44-51. [CrossRef]

24. Lin, C.; Choy, K.L.; Ho, G.T.; Chung, S.H.; Lam, H. Survey of green vehicle routing problem: Past and future trends. Expert Syst. Appl. 2014, 41, 1118-1138. [CrossRef]

25. Asghari, M.; Al-e, S.M.J.M. Green vehicle routing problem: A state-of-the-art review. Int. J. Prod. Econ. 2020, $231,107899$. [CrossRef]

26. Moghdani, R.; Salimifard, K.; Demir, E.; Benyettou, A. The green vehicle routing problem: A systematic literature review. J. Clean. Prod. 2020, 279, 123691. [CrossRef]

27. Ren, R.; Hu, W.; Dong, J.; Sun, B.; Chen, Y.; Chen, Z. A systematic literature review of green and sustainable logistics: Bibliometric analysis, research trend and knowledge taxonomy. Int. J. Environ. Res. Public Health 2020, 17, 261. [CrossRef]

28. Patella, S.M.; Grazieschi, G.; Gatta, V.; Marcucci, E.; Carrese, S. The Adoption of Green Vehicles in Last Mile Logistics: A Systematic Review. Sustainability 2020, 13, 6. [CrossRef]

29. Sawik, B.; Faulin, J.; Pérez-Bernabeu, E. Multi-criteria optimization for fleet size with environmental aspects. Transp. Res. Procedia 2017, 27, 61-68. [CrossRef]

30. Serrano-Hernández, A.; Juan, A.A.; Faulin, J.; Perez-Bernabeu, E. Horizontal collaboration in freight transport: concepts, benefits and environmental challenges. SORT 2017, 1, 393-414.

31. Serrano-Hernandez, A.; Faulin, J.; Hirsch, P.; Fikar, C. Agent-based simulation for horizontal cooperation in logistics and transportation: From the individual to the grand coalition. Simul. Model. Pract. Theory 2018, 85, 47-59. [CrossRef]

32. Quintero-Araujo, C.L.; Gruler, A.; Juan, A.A.; Faulin, J. Using horizontal cooperation concepts in integrated routing and facility-location decisions. Int. Trans. Oper. Res. 2019, 26, 551-576. [CrossRef]

33. Santos, M.J.; Amorim, P.; Marques, A.; Carvalho, A.; Póvoa, A. The vehicle routing problem with backhauls towards a sustainability perspective: A review. TOP 2019, 1-44. [CrossRef]

34. Belloso, J.; Juan, A.A.; Faulin, J. An iterative biased-randomized heuristic for the fleet size and mix vehicle-routing problem with backhauls. Int. Trans. Oper. Res. 2019, 26, 289-301. [CrossRef]

35. Juan, A.A.; Faulin, J.; Ruiz, R.; Barrios, B.; Gilibert, M.; Vilajosana, X. Using Oriented Random Search to Provide a Set of Alternative Solutions to the Capacitated Vehicle Routing Problem. In Operations Research and Cyber-Infrastructure; Chinneck, J.W., Kristjansson, B., Saltzman, M.J., Eds.; Springer: Boston, MA, USA, 2009; pp. 331-345.

36. Archetti, C.; Savelsbergh, M.; Speranza, M.G. The vehicle routing problem with occasional drivers. Eur. J. Oper. Res. 2016, 254, 472-480. [CrossRef]

37. Sampaio, A.; Savelsbergh, M.; Veelenturf, L.; Van Woensel, T. Crowd-based city logistics. In Sustainable Transportation and Smart Logistics; Elsevier: Amsterdam, The Netherlands, 2019; pp. 381-400. 
38. McKinnon, A. Crowdshipping: A Communal Approach to Reducing Urban Traffic Levels? Kühne Logistics University: Hamburg, Germany, 2016.

39. Deloison, T.; Hannon, E.; Huber, A.; Heid, B.; Klink, C.; Sahay, R.; Wolff, C. The Future of the Last-Mile Ecosystem; World Economic Forum: Cologny, Switzerland, 2020.

40. Kirschstein, T. Comparison of energy demands of drone-based and ground-based parcel delivery services. Transp. Res. Part D Transp. Environ. 2020, 78, 102209. [CrossRef]

41. Figliozzi, M.A. Carbon emissions reductions in last mile and grocery deliveries utilizing air and ground autonomous vehicles. Transp. Res. Part D Transp. Environ. 2020, 85, 102443. [CrossRef]

42. Hübner, A.H.; Kuhn, H.; Wollenburg, J.; Towers, N.; Kotzab, H. Last mile fulfilment and distribution in omni-channel grocery retailing: A strategic planning framework. Int. J. Retail. Distrib. Manag. 2016. [CrossRef]

43. Barceló, J. Future trends in sustainable transportation. In Sustainable Transportation and Smart Logistics; Elsevier: Amsterdam, The Netherlands, 2019; pp. 401-435.

44. Del Vecchio, P.; Secundo, G.; Maruccia, Y.; Passiante, G. A system dynamic approach for the smart mobility of people: Implications in the age of big data. Technol. Forecast. Soc. Chang. 2019, 149, 119771. [CrossRef]

45. Juan, A.A.; Mendez, C.; Faulin, J.; De Armas, J.; Grasman, S. Electric vehicles in logistics and transportation: A survey on emerging environmental, strategic, and operational challenges. Energies 2016, 9, 86.

46. Meyer, T. Decarbonizing road freight transportation-A bibliometric and network analysis. Transp. Res. Part D Transp. Environ. 2020, 89, 102619. [CrossRef]

47. Bravo, J.J.; Vidal, C.J. Freight transportation function in supply chain optimization models: A critical review of recent trends. Expert Syst. Appl. 2013, 40, 6742-6757. [CrossRef]

48. Pérez, J.C.; Carrillo, M.H.; Montoya-Torres, J.R. Multi-criteria approaches for urban passenger transport systems: A literature review. Ann. Oper. Res. 2015, 226, 69-87. [CrossRef]

49. Crainic, T.G.; Ricciardi, N.; Storchi, G. Models for Evaluating and Planning City Logistics Systems. Transp. Sci. 2009, 43, 432-454. [CrossRef]

50. Agatz, N.; Erera, A.; Savelsbergh, M.; Wang, X. Optimization for dynamic ride-sharing: A review. Eur. J. Oper. Res. 2012, 223, 295-303. [CrossRef]

51. Ferrero, F.; Perboli, G.; Rosano, M.; Vesco, A. Car-sharing services: An annotated review. Sustain. Cities Soc. 2018, 37, 501-518. [CrossRef]

52. Liotta, G.; Stecca, G.; Kaihara, T. Optimisation of freight flows and sourcing in sustainable production and transportation networks. Int. J. Prod. Econ. 2015, 164, 351-365. [CrossRef]

53. Sun, Y.; Lang, M.; Wang, D. Optimization Models and Solution Algorithms for Freight Routing Planning Problem in the Multi-Modal Transportation Networks: A Review of the State-of-the-Art. Open Civ. Eng. J. 2015, 9, 714-723. [CrossRef]

54. Christiansen, M.; Fagerholt, K.; Nygreen, B.; Ronen, D. Ship routing and scheduling in the new millennium. Eur. J. Oper. Res. 2013, 228, 467-483. [CrossRef]

55. Tian, Y.; Ye, B.; Xing, D. Cruise Flight Performance Optimization for Minimizing Green Direct Operating Cost. Sustainability 2019, 11, 3899. [CrossRef]

56. Yin, Y.; Lawphongpanich, S. Internalizing emission externality on road networks. Transp. Res. Part D 2006, 11, 292-301. [CrossRef]

57. Aziz, H.; Ukkusuri, S.V.; Zhan, X. Determining the Impact of Personal Mobility Carbon Allowance Schemes in Transportation Networks. Netw. Spat. Econ. 2017, 17, 505-545. [CrossRef]

58. Farahani, R.Z.; Miandoabchi, E.; Szeto, W.; Rashidi, H. A review ofurban transportation network design problems. Eur. J. Oper. Res. 2013, 229, 281-302. [CrossRef]

59. Miralinaghi, M.; Lou, Y.; Keskin, B.B.; Zarrinmehr, A.; Shabanpour, R. Refueling station location problem with traffic deviation considering route choice and demand uncertainty. Int. J. Hydrogen Energy 2017, 42, 3335-3351. [CrossRef]

60. Cavadas, J.; de Almeida Correia, G.; Gouveia, J. A MIP model for locating slow-charging stations for electric vehicles in urban areas accounting for driver tours. Transp. Res. Part E 2015, 75, 188-201. [CrossRef]

61. Kim, J.G.; Kuby, M. The deviation-flow refueling location model for optimizing a network of refueling stations. Int. J. Hydrog. Energy 2012, 37, 5406-5420. [CrossRef]

62. Abdullahi, H.; Reyes-Rubiano, L.; Ouelhadj, D.; Faulin, J.; Juan, A.A. Modelling and multi-criteria analysis of the sustainability dimensions for the green vehicle routing problem. Eur. J. Oper. Res. 2020, 229, 281-302. [CrossRef]

63. Yang, X.; Li, X.; Ning, B. A Survey on Energy-Efficient Train Operation for Urban Rail Transit. IEEE Trans. Intell. Transp. Syst. 2016, 17, 2-13. [CrossRef]

64. Onggo, B.; Corlu, C.G.; Juan, A.A.; Monks, T.; de la Torre, R. Combining Symbiotic Simulation Systems with Enterprise Data Storage Systems for Real-Time Decision Making. Enterp. Inf. Syst. 2020. [CrossRef]

65. Rabe, M.; Goldsman, D. Decision Making Using Simulation Methods in Sustainable Transportation. In Sustainable Transportation and Smart Logistics; Elsevier: Amsterdam, The Netherlands, 2019; pp. 305-333.

66. Benzaman, B.; Al-Dhaheri, A.; Claudio, D. Discrete event simulation of green supply chain with traffic congestion factor. In Proceedings of the 2016 Winter Simulation Conference (WSC), Washington, DC, USA, 11-14 December 2016; pp. $1654-1665$.

67. Pruckner, M.; German, R. The impact of electric vehicles on the german energy system. In Proceedings of the 49th Annual Simulation Symposium, Pasadena, CA, USA, 3-6 April 2016; pp. 1-7. 
68. Doluweera, G.; Hahn, F.; Bergerson, J.; Pruckner, M. A scenario-based study on the impacts of electric vehicles on energy consumption and sustainability in Alberta. Appl. Energy 2020, 268, 114961. [CrossRef]

69. Fagnant, D.J.; Kockelman, K.M. The travel and environmental implications of shared autonomous vehicles, using agent-based model scenarios. Transp. Res. Part C Emerg. Technol. 2014, 40,1-13. [CrossRef]

70. Dlugosch, O.; Brandt, T.; Neumann, D. Combining analytics and simulation methods to assess the impact of shared, autonomous electric vehicles on sustainable urban mobility. Inf. Manag. 2020, 103285, doi:10.1016/j.im.2020.103285. [CrossRef]

71. Jordan, W.C. Transforming Personal Mobility. Available online: http://wordpress.ei.columbia.edu/mobility/files/2012/12/ Transforming-Personal-Mobility-Aug-10-2012.pdf (accessed on 28 November 2020).

72. Danloup, N.; Mirzabeiki, V.; Allaoui, H.; Goncalves, G.; Julien, D.; Mena, C. Reducing transportation greenhouse gas emissions with collaborative distribution: A case study. Manag. Res. Rev. 2015, 38, 1049-1067. [CrossRef]

73. Hoffa-Dabrowska, P.; Grzybowska, K. Simulation modeling of the sustainable supply chain. Sustainability 2020, $12,6007$. [CrossRef]

74. Rabe, M.; Sari, M.U.; Fechteler, T.; Ruini, L.F. Discrete event simulation as a strategic decision instrument for a CO2-and cost-efficient distribution chain applied in the FMCG sector. Int. J. Adv. Logist. 2015, 4, 47-53. [CrossRef]

75. Van Der Vorst, J.G.; Tromp, S.O.; Zee, D.J.V.D. Simulation modelling for food supply chain redesign; integrated decision making on product quality, sustainability and logistics. Int. J. Prod. Res. 2009, 47, 6611-6631. [CrossRef]

76. Lokhandwala, M.; Cai, H. Dynamic ride sharing using traditional taxis and shared autonomous taxis: A case study of NYC. Transp. Res. Part C Emerg. Technol. 2018, 97, 45-60. [CrossRef]

77. Karakikes, I.; Nathanail, E. Simulation techniques for evaluating smart logistics solutions for sustainable urban distribution. Procedia Eng. 2017, 178, 569-578. [CrossRef]

78. Zhou, X.; Kuhl, M.E. Design and development of a sustainability toolkit for simulation. In Proceedings of the 2010 Winter Simulation Conference, Baltimore, MD, USA, 5-8 December 2010; pp. 1601-1612.

79. Ylén, J.P.; Hölttä, V. System Dynamics-A Tool for Designing and Analysing Complex Processes. Simul. News Eur. 2007, 17, 27-31.

80. Bischoff, J.; Maciejewski, M. Current and Future Dynamic Passenger Transport Services-Modeling, Simulation, and Optimization in a Sustainable Transport System. In Sustainable Transportation and Smart Logistics; Elsevier: Amsterdam, The Netherlands, 2019; pp. 337-360.

81. Gonzalez-Martin, S.; Juan, A.A.; Riera, D.; Elizondo, M.G.; Ramos, J.J. A simheuristic algorithm for solving the arc routing problem with stochastic demands. J. Simul. 2018, 12, 53-66. [CrossRef]

82. Rabe, M.; Deininger, M.; Juan, A.A. Speeding up computational times in simheuristics combining genetic algorithms with discrete-event simulation. Simul. Model. Pract. Theory 2020, 103, 102089. [CrossRef]

83. Gutenschwager, K.; Alicke, K. Supply Chain Simulation mit ICON-SimChain. In Logistik Management; Springer: Berlin/Heidelberg, Germany, 2004; pp. 161-178.

84. Zambrano, J.L.; Calafate, C.T.; Soler, D.; Cano, J.C.; Manzoni, P. Using real traffic data for its simulation: Procedure and validation. In Proceedings of the 2016 Intl IEEE Conferences on Ubiquitous Intelligence \& Computing, Advanced and Trusted Computing, Scalable Computing and Communications, Cloud and Big Data Computing, Internet of People, and Smart World Congress (UIC/ATC/ScalCom/CBDCom/IoP/SmartWorld), Toulouse, France, 18-21 July 2016; pp. 161-170.

85. Nguyen, T.V.; Krajzewicz, D.; Fullerton, M.; Nicolay, E. DFROUTER-Estimation of vehicle routes from cross-section measurements. In Modeling Mobility with Open Data; Springer: Berlin/Heidelberg, Germany, 2015; pp. 3-23.

86. Krajzewicz, D.; Hertkorn, G.; Rössel, C.; Wagner, P. SUMO (Simulation of Urban MObility)-an open-source traffic simulation. In Proceedings of the 4th Middle East Symposium on Simulation and Modelling (MESM20002), Sharjah, United Arab Emirates, September 2002; pp. 183-187.

87. Zambrano-Martinez, J.L.; Calafate, C.T.; Soler, D.; Lemus-Zúñiga, L.G.; Cano, J.C.; Manzoni, P.; Gayraud, T. A Centralized Route-Management Solution for Autonomous Vehicles in Urban Areas. Electronics 2019, 8, 722. [CrossRef]

88. Patel, A.; Venkateswaran, J.; Mathew, T.V. Optimal signal control for pre-timed signalized junctions with uncertain traffic: Simulation based optimization approach. In Proceedings of the 2015 Winter Simulation Conference (WSC), Huntington Beach, CA, USA, 6-9 December 2015; pp. 3168-3169.

89. Li, X.; Khattak, A.J.; Kohls, A.G. Signal phase timing impact on traffic delay and queue length-a intersection case study. In Proceedings of the 2016 Winter Simulation Conference (WSC), Washington, DC, USA, 11-14 December 2016; pp. 3722-3723.

90. Benzaman, B.; Sharma, D. Discrete event simulation of a road intersection integrating V2V and V2I features to improve traffic flow. In Proceedings of the 2017 Winter Simulation Conference (WSC), Las Vegas, NV, USA, 3-6 December 2017; pp. 3054-3065.

91. Fikar, C.; Juan, A.A.; Martinez, E.; Hirsch, P. A discrete-event driven metaheuristic for dynamic home service routing with synchronised trip sharing. Eur. J. Ind. Eng. 2016, 10, 323-340. [CrossRef]

92. Alonso-Mora, J.; Samaranayake, S.; Wallar, A.; Frazzoli, E.; Rus, D. On-demand high-capacity ride-sharing via dynamic trip-vehicle assignment. Proc. Natl. Acad. Sci. USA 2017, 114, 462-467. [CrossRef]

93. Longo, M.; Lutz, N.M.; Daniel, L.; Zaninelli, D.; Pruckner, M. Towards an impact study of electric vehicles on the italian electric power system using simulation techniques. In Proceedings of the 2017 IEEE 3rd International Forum on Research and Technologies for Society and Industry (RTSI), Modena, Italy, 11-13 September 2017; pp. 1-5.

94. Narayanan, S.; Chaniotakis, E.; Antoniou, C. Shared autonomous vehicle services: A comprehensive review. Transp. Res. Part C Emerg. Technol. 2020, 111, 255-293. [CrossRef] 
95. Antoniou, C.; Dimitriou, L.; Pereira, F. Mobility Patterns, Big Data and Transport Analytics: Tools and Applications for Modeling; Elsevier: Amsterdam, The Netherlands, 2018.

96. Zhou, X.; Wang, M.; Li, D. Bike-sharing or taxi? Modeling the choices of travel mode in Chicago using machine learning. J. Transp. Geogr. 2019, 79, 102479.

97. Yang, Y.; Heppenstall, A.; Turner, A.; Comber, A. Using graph structural information about flows to enhance short-term demand prediction in bike-sharing systems. Comput. Environ. Urban Syst. 2020, 83, 101521. [CrossRef]

98. Zhou, Q.; Wong, C.J.; Su, X. Machine Learning Approach to Quantity Management for Long-Term Sustainable Development of Dockless Public Bike: Case of Shenzhen in China. J. Adv. Transp. 2020, 2020, 8847752. [CrossRef]

99. Basu, R.; Ferreira, J. Understanding household vehicle ownership in Singapore through a comparison of econometric and machine learning models. Transp. Res. Procedia 2020, 48, 1674-1693. [CrossRef]

100. Migliore, M.; Burgio, A.L.; Di Giovanna, M. Parking pricing for a sustainable transport system. Transp. Res. Procedia 2014, 3, 403-412. [CrossRef]

101. Ali Khalil, M.; Hamad, K.; Shanableh, A. Developing machine learning models to predict roadway traffic noise: An opportunity to escape conventional techniques. Transp. Res. Rec. 2019, 2673, 158-172. [CrossRef]

102. Tang, T.; Liu, R.; Choudhury, C. Incorporating weather conditions and travel history in estimating the alighting bus stops from smart card data. Sustain. Cities Soc. 2020, 53, 101927. [CrossRef]

103. Majumdar, S.; Subhani, M.M.; Roullier, B.; Anjum, A.; Zhu, R. Congestion prediction for smart sustainable cities using IoT and machine learning approaches. Sustain. Cities Soc. 2020, 64, 102500. [CrossRef]

104. Liang, L.; Xu, M.; Grant-Muller, S.; Mussone, L. Household travel mode choice estimation with large-scale data-An empirical analysis based on mobility data in Milan. Int. J. Sustain. Transp. 2019. [CrossRef]

105. Giret, A.; Carrascosa, C.; Julian, V.; Rebollo, M.; Botti, V. A crowdsourcing approach for sustainable last mile delivery. Sustainability 2018, 10, 4563. [CrossRef]

106. Hasan, U.; Whyte, A.; Al Jassmi, H. A Review of the Transformation of Road Transport Systems: Are We Ready for the Next Step in Artificially Intelligent Sustainable Transport? Appl. Syst. Innov. 2020, 3, 1. [CrossRef]

107. Nandal, M.; Mor, N.; Sood, H. An Overview of Use of Artificial Neural Network in Sustainable Transport System. Comput. Methods Data Eng. 2020, 1227, 83-91.

108. Asensio, O.I.; Alvarez, K.; Dror, A.; Wenzel, E.; Hollauer, C.; Ha, S. Real-time data from mobile platforms to evaluate sustainable transportation infrastructure. Nat. Sustain. 2020, 3, 463-471. [CrossRef]

109. Consilvio, A.; Solís-Hernández, J.; Jiménez-Redondo, N.; Sanetti, P.; Papa, F.; Mingolarra-Garaizar, I. On Applying Machine Learning and Simulative Approaches to Railway Asset Management: The Earthworks and Track Circuits Case Studies. Sustainability 2020, 12, 2544. [CrossRef]

110. Dimić, S.; Pamučar, D.; Ljubojević, S.; Đorović, B. Strategic transport management models—The case study of an oil industry. Sustainability 2016, 8, 954. [CrossRef]

111. Mohagheghi, V.; Mousavi, S.M.; Aghamohagheghi, M.; Vahdani, B. A new approach of multi-criteria analysis for the evaluation and selection of sustainable transport investment projects under uncertainty: A case study. Int. J. Comput. Intell. Syst. 2017, 10, 605-626. [CrossRef]

112. Ülengin, F.; Işık, M.; Ekici, Ş.Ö.; Özaydın, Ö.; Kabak, Ö.; Topçu, Y.İ. Policy developments for the reduction of climate change impacts by the transportation sector. Transp. Policy 2018, 61, 36-50. [CrossRef]

113. de Paula, L.B.; Marins, F.A.S. Algorithms applied in decision-making for sustainable transport. J. Clean. Prod. 2018, 176, 1133-1143. [CrossRef]

114. Zhang, X.; Onieva, E.; Perallos, A.; Osaba, E.; Lee, V.C. Hierarchical fuzzy rule-based system optimized with genetic algorithms for short term traffic congestion prediction. Transp. Res. Part C Emerg. Technol. 2014, 43, 127-142. [CrossRef]

115. Jasti, P.C.; Ram, V.V. Integrated performance assessment and service level benchmarking of urban bus system using fuzzy logic. Eur. Transp. Trasp. Eur. 2018, 69, 1-14.

116. Sun, Y.; Li, X.; Liang, X.; Zhang, C. A bi-objective fuzzy credibilistic chance-constrained programming approach for the hazardous materials road-rail multimodal routing problem under uncertainty and sustainability. Sustainability 2019, 11, 2577. [CrossRef]

117. Tadić, S.; Krstić, M.; Roso, V.; Brnjac, N. Planning an intermodal terminal for the sustainable transport networks. Sustainability 2019, 11, 4102. [CrossRef]

118. Haider, S.W.; Zhuang, G.; Ali, S. Identifying and bridging the attitude-behavior gap in sustainable transportation adoption. J. Ambient. Intell. Humaniz. Comput. 2019, 10, 3723-3738. [CrossRef]

119. Kaya, S.K.; Erginel, N. Futuristic airport: A sustainable airport design by integrating hesitant fuzzy SWARA and hesitant fuzzy sustainable quality function deployment. J. Clean. Prod. 2020, 275, 123880. [CrossRef]

120. Kisgyörgy, L.; Tóth, J. Fuzzy analysis of comfort along travel chains. Transport 2020, 35, 203-212. [CrossRef]

121. Shekhovtsov, A.; Kozlov, V.; Nosov, V.; Sałabun, W. Efficiency of Methods for Determining the Relevance of Criteria in Sustainable Transport Problems: A Comparative Case Study. Sustainability 2020, 12, 7915. [CrossRef]

122. Zagorskas, J.; Turskis, Z. Setting priority list for construction works of bicycle path segments based on Eckenrode rating and ARAS-F decision support method integrated in GIS. Transport 2020, 35, 179-192. [CrossRef]

123. Singh, A.; Gurtu, A.; Singh, R.K. Selection of sustainable transport system: A case study. Manag. Environ. Qual. Int. J. 2020. [CrossRef] 
124. Wątróbski, J.; Małecki, K.; Kijewska, K.; Iwan, S.; Karczmarczyk, A.; Thompson, R.G. Multi-criteria analysis of electric vans for city logistics. Sustainability 2017, 9, 1453. [CrossRef]

125. Tsang, Y.P.; Wong, W.C.; Huang, G.; Wu, C.H.; Kuo, Y.; Choy, K.L. A Fuzzy-Based Product Life Cycle Prediction for Sustainable Development in the Electric Vehicle Industry. Energies 2020, 13, 3918. [CrossRef]

126. Cantarella, G.E.; Fedele, V. Fuzzy utility theory for analysing discrete choice behaviour. In Proceedings of the Fourth International Symposium on Uncertainty Modeling and Analysis (ISUMA 2003), College Park, MD, USA, 21-24 September 2003; pp. 148-154.

127. Ramazani, H.; Shafahi, Y.; Seyedabrishami, S. A fuzzy traffic assignment algorithm based on driver perceived travel time of network links. Sci. Iran. 2011, 18, 190-197. [CrossRef]

128. Miralinaghi, M.; Shafahi, Y.; Shabanpour Anbarani, R. A fuzzy network assignment model based on user equilibrium condition. Sci. Iran. 2015, 22, 2012-2023.

129. Miralinaghi, M.; Lou, Y.; Hsu, Y.T.; Shabanpour, R.; Shafahi, Y. Multiclass fuzzy user equilibrium with endogenous membership functions and risk-taking behaviors. J. Adv. Transp. 2016, 50, 1716-1734. [CrossRef]

130. Waage, S.A. Re-considering product design: A practical "road-map" for integration of sustainability issues. J. Clean. Prod. 2007, 15, 638-649. [CrossRef]

131. Bertoni, M. Introducing sustainability in value models to support design decision making: A systematic review. Sustainability 2017, 9, 994. [CrossRef]

132. Howard-Grenville, J.; Davis, G.F.; Dyllick, T.; Miller, C.C.; Thau, S.; Tsui, A.S. Sustainable development for a better world: Contributions of leadership, management, and organizations. Acad. Manag. Discov. 2019, 5, 355-366. [CrossRef]

133. Calabrese, A.; Costa, R.; Levialdi, N.; Menichini, T. Integrating sustainability into strategic decision-making: A fuzzy AHP method for the selection of relevant sustainability issues. Technol. Forecast. Soc. Chang. 2019, 139, 155-168. [CrossRef]

134. Wu, Z.; Pagell, M. Balancing priorities: Decision-making in sustainable supply chain management. J. Oper. Manag. 2011, 29, 577-590. [CrossRef]

135. Chofreh, A.G.; Goni, F.A. Review of frameworks for sustainability implementation. Sustain. Dev. 2017, 25, 180-188. [CrossRef]

136. Kleine, A.; Von Hauff, M. Sustainability-driven implementation of corporate social responsibility: Application of the integrative sustainability triangle. J. Bus. Ethics 2009, 85, 517. [CrossRef]

137. Mustafee, N.; Harper, A.; Onggo, B.S. Hybrid Modelling and Simulation (M\&S): Driving Innovation in the Theory and Practice of M\&S. In Proceedings of the 2020 Winter Simulation Conference (WSC), Orlando, FL, USA, 13-16 December 2020; pp. 3140-3151.

138. Juan, A.A.; Kelton, W.D.; Currie, C.S.; Faulin, J. Simheuristics applications: Dealing with uncertainty in logistics, transportation, and other supply chain areas. In Proceedings of the 2018 Winter Simulation Conference, Gothenburg, Sweden, 9-12 December 2018; pp. 3048-3059.

139. Arnau, Q.; Juan, A.A.; Serra, I. On the use of learnheuristics in vehicle routing optimization problems with dynamic inputs. Algorithms 2018, 11, 208. [CrossRef] 